STUDI

FRANCESI

\section{Studi Francesi}

Rivista quadrimestrale fondata da Franco Simone

174 (LVIII | III) | 2014

Varia

\title{
Aa. Vv., Réception et créativité. Le cas de Stendhal dans la littérature japonaise moderne et contemporaine, t. II, édité par Julie Brock
}

\section{Michel Arrous}

\section{(2) OpenEdition}

Journals

Édition électronique

URL : http://journals.openedition.org/studifrancesi/1546

DOI : 10.4000/studifrancesi. 1546

ISSN : 2421-5856

Éditeur

Rosenberg \& Sellier

\section{Édition imprimée}

Date de publication : 1 novembre 2014

Pagination : 616-617

ISSN : 0039-2944

\section{Référence électronique}

Michel Arrous, «Aa. VV., Réception et créativité. Le cas de Stendhal dans la littérature japonaise moderne et contemporaine, t. II, édité par Julie Brock », Studi Francesi [En ligne], 174 (LVIII | III) | 2014, mis en ligne le 01 novembre 2014, consulté le 18 septembre 2020. URL : http://journals.openedition.org/

studifrancesi/1546; DOI : https://doi.org/10.4000/studifrancesi.1546

Ce document a été généré automatiquement le 18 septembre 2020.

\section{cc) $(9)$}

Studi Francesi è distribuita con Licenza Creative Commons Attribuzione - Non commerciale - Non opere derivate 4.0 Internazionale. 


\title{
Aa. Vv., Réception et créativité. Le cas de Stendhal dans la littérature japonaise moderne et contemporaine, $t$. II, édité par Julie Brock
}

\author{
Michel Arrous
}

\section{RÉFÉRENCE}

AA. VV., Réception et créativité. Le cas de Stendhal dans la littérature japonaise moderne et contemporaine, t. II, édité par Julie BROcK, Berne, Peter Lang, 2013, pp. 440.

1 Avec ce volume qui fait suite à un premier recueil d'actes publié en 2011 , on dispose d'un large choix d'études sur la réception des œuvres occidentales au Japon, plus précisément sur les effets de leur lecture sur la création des écrivains japonais. La théorie supposée sous-tendre l'ensemble est celle de l'«effet de vie» formalisée par Marc-Mathieu Munch, théorie qui devrait permettre à chaque lecteur d'analyser sa propre expérience de lecture. L'interaction du lecteur et de l'œuvre est illustrée par le cas de Stendhal avec lequel les lecteurs japonais entretiennent de longue date une relation privilégiée. Mais il est aussi question de la chimie de la traduction, de l'«impact» de Verlaine sur la création de Feux, roman de Öoka Shôhei (1952), de la difficile traduction en japonais des Mémoires d'outre-tombe, de la redécouverte de Dostoïevski, ou de la réception de Charles Cros, poète fort peu connu au Japon.

Une douzaine de contributions sont consacrées à Stendhal ou aux œuvres japonaises dont les auteurs ont subi l'influence. C'est le cas du premier introducteur de Stendhal au japon, Ueda Bin (1874-1916), présenté par Hiroko oGAWA (L'influence de Stendhal dans le roman "Tourbillon" d'Ueda Bin, pp. 69-76). Cinq chapitres de ce roman publié en 1910 sont sous le signe de Stendhal maître d'énergie et modèle de l'homme moderne; on y décèle aussi un emploi du monologue intérieur qui rappelle, du moins pour certains 
thèmes, la pratique de l'auteur du Rouge et le Noir. La présence de Stendhal est un élément essentiel de ce roman; malheureusement, elle n'a pas suffi à séduire le public. Hiroshi MATSUMARA lit le roman de 1839 comme l'occasion pour chacun de réfléchir à sa position d'écrivain ("Études" sur M. Beyle comme un lieu de rencontre de trois vies: Balzac, Stendhal et Ôoka, pp. 95-108). Balzac refait la Chartreuse, Stendhal envisage un temps d'en réécrire une partie et abandonne ce projet, choix qu'approuve Ôoka dans ses Études sur Stendhal (1944). Comme l'expérience de la guerre et de la captivité modifieront sa compréhension de Stendhal, la lecture de la Chartreuse influencera son point de vue sur la guerre. Que lit-on en vérité quand on lit une traduction? C'est la question que pose Michaël ЈАКОВ, à partir du souvenir d'une première lecture du Rouge en allemand (De Stendhal à Stendhal: les enjeux de la traduction allemande du "Rouge et le Noir", pp. 159- 167). La comparaison de deux passages, dans les traductions d'Arthur Schurig (1922) et d'Elisabeth Edl (2004) - cette dernière unanimement saluée et jugée «hyper-exacte» pointe entre les deux versions un écart considérable qu'explique le point de vue adopté. Pour la plus récente, l'écart temporel a permis une version plus fiable. Le même problème se pose avec la réception de Stendhal au Japon où le Rouge a été traduit 59 fois entre 1900 et 1998. La nouvelle traduction, par Nozaki Kan (2007), a fait l'objet d'un débat. Le traducteur a d'ailleurs expliqué ou justifié ses choix (voir t. I, pp. 65-71) que Keiko sugiмото examine en montrant le profit tiré des notes et de l'appareil critique des éditions de P.-G. Castex et Y. Ansel (Du bon usage des éditions critiques pour la traduction japonaise: le cas du "Rouge et le Noir", pp. 169-178). En forme de lettre, Claudio GALDERISI (Stendhal traducteur, pp. 189-191) déçoit fortement: l'étude annoncée de la réécriture des manuscrits italiens est escamotée; quant à l'évocation du "phénomène d'appropriation par l'effacement», on la jugera pour le moins rapide. Julie BROCK a eu la patience d'identifier les citations dont Ôoka, qui n'indique pas ses sources, a parsemé son Essai sur Stendhal (1936) (En traduisant les études stendhaliennes d'Ôoka Shôhei - Les effets rendus par une citation, pp. 201-212). Bel effort illustré par l'étude d'un montage à partir d'une lettre de Mme Ancelot à Stendhal et d'une autre de ce dernier à Alberthe de Rubempré, toutes deux concernant le Rouge.

3 Une section entière est réservée à "Stendhal lecteur, amateur de musique et de peinture». Béatrice DIDIER (Stendhal, les moralistes et l'apprentissage du théâtre, pp. 309-318), relève dans le journal de Beyle, pour les années 1802-1804, un intérêt soutenu pour les moralistes des XVII et XVIII siècles. Chez Beyle qui n'est pas encore Stendhal, il $\mathrm{y}$ a un diariste moraliste qui intègre la maxime au portrait, en fait le cœur d'une anecdote ou d'un caractère dramatique. Contrairement à ce que l'on croit, pour Stendhal, la patrie de l'amour n'est pas l'Italie, mais l'Arabie où règnerait l'égalité entre amants. Yuchi KASUYA prend la précaution de préciser que L'Arabie de Stendhal (pp. 319-327) est fantasmée à partir d'une lecture des Mille et Une Nuits, quelque peu modifiée par les informations communiquées par Fauriel. Akemi чамамото voit en Manon Roland la première des happy few et le modèle d'une lectrice idéale (pp. 329-334). Les rapports entre l'égérie des Girondins et le républicain Stendhal sont étroits: tous deux ont le même regard sur leur époque, sur les autres et sur eux-mêmes. Sur les pas de Philippe Berthier, Ami ковАYASHI analyse la fonction des commentaires sur la penture dans les romans de Stendhal où la référence picturale renvoie plus à l'impression qu'à l'expression (Le rôle et l'importance de la peinture dans l'œuvre de création de Stendhal, notamment dans les portraits des personnages, pp. 335-343). À partir d'un contresens, ou plutôt d'une lecture tendancieuse d'un passage des Promenades avec Mozart de Ghéon 
(1932), Nobuhiro TAKAKI propose d'interpréter l'image que le critique Kobayashi (1902-1983) donne de Stendhal dans son Mozart (1946), un Stendhal qui aurait trouvé en lui-même «l'esprit de la musique» ("Mozart" de Kobayashi Hideo - Stendhal, émule des symbolistes, pp. 345-356).

4 Ces études sur les rapports de l'adaptation, dont les aléas sont connus, à la création démontrent qu'une bonne réception suppose de la part du lecteur une participation active qui ne peut être bénéfique que si le texte traduit est lu comme une œuvre originale écrite dans sa propre langue. Alors l'œuvre est réussie. 